\title{
A Young Male Patient Presented with Dyspnea, Cough, and Bilateral Pulmonary Infiltrations: What is Your Diagnosis?
}

\author{
Sinem İliaz ${ }^{1}$, Ece Yurtseven², Benan Niku Çağlayann ${ }^{1}$ \\ ${ }^{1}$ Department of Pulmonary Medicine, Koç University Hospital, İstanbul, Turkey \\ ${ }^{2}$ Department of Cardiology, Koç University Hospital, İstanbul, Turkey
}

A 38-year-old male who never smoked, who did not take any medication regularly, and who did not have any comorbid disease applied to the outpatient clinic of Chest Diseases with complaints of shortness of breath that had started a week previously and had gradually become more severe; cough that occurred as attacks, particularly at night; and mild retrosternal pain/burn associated with effort. His medical history revealed that he had applied to the outpatient clinics of Cardiology and Internal Medicine due to similar complaints two months ago. An echocardiography examination demonstrated no pathology except a pericardial effusion with a thickness of $0.4 \mathrm{~cm}$ localized in the posterior part of the right atrium, and the patient's chest radiography results were normal (Figure 1). In his medical history, it was learned that the shortness of breath had regressed after antibiotic therapy given due to a pre-diagnosis of upper respiratory tract infection, but had not completely healed. When his occupational history was questioned, it was learned that he worked in an office. However, he had been exposed to excessive amounts of dust from construction work in the office for approximately two months. He had no features in his familial history except breast cancer for his mother and diabetes mellitus for his father.

During his physical examination, his general condition was good; he did not have fever, edema, icterus, or cyanosis. However, he was mildly tachypneic. In the evaluation of his vital signs, his respiratory rate was $24 / \mathrm{min}$, his arterial blood pressure was $134 / 80$ $\mathrm{mmHg}$, his body temperature was $36.7^{\circ} \mathrm{C}$, his pulse was $122 / \mathrm{min}$ and rhythmic, and his peripheral oxygen saturation $\left(\mathrm{SpO}_{2}\right)$ was $88 \%-$ $89 \%$ (at room temperature). His lung sounds were bilaterally normal while resting, and no abnormality was found in examinations of other systems.

Received Date: 28.06.2016 Accepted Date: 20.08.2016 DOI: 10.5152/ejp.2016.74755 Corresponding Author Sinem İliaz

E-mail: snmkaraosman@gmail.com

- Available online at www.eurasianjpulmonol.com Commons Attribution-NonCommercial
In his laboratory analyses, his $C$ reactive protein (CRP) level was $10 \mathrm{mg} / \mathrm{L}$. His leukocyte count and formula were normal. His pulmonary function test revealed his FVC to be 4240 $\mathrm{mL}(85 \%), \mathrm{FEV}_{1}$ to be $3690 \mathrm{~mL}(89 \%)$, $\mathrm{FEV}_{1} / \mathrm{FVC}$ to be $87 \%$, DLCO to be $83 \%$, and DLCO/VA to be $94 \%$.

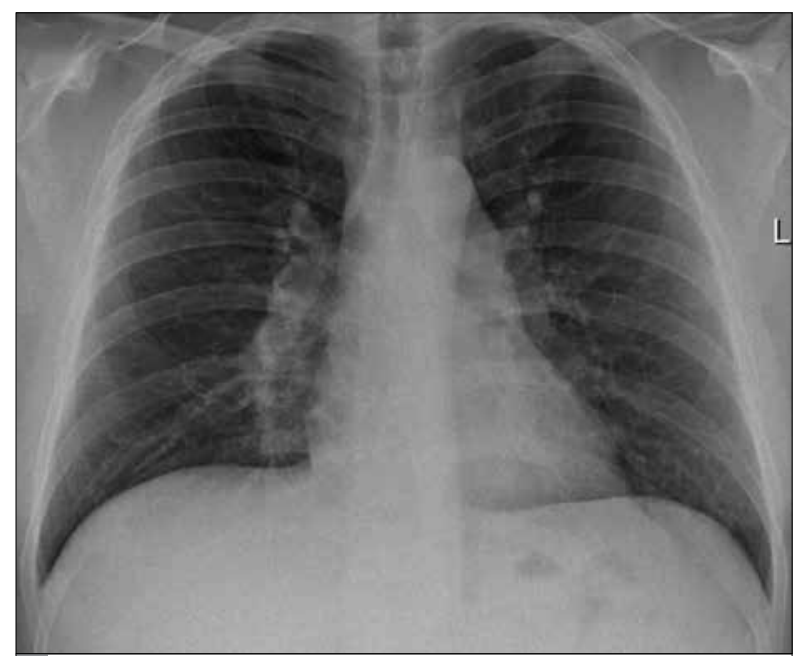

Figure 1. Posteroanterior chest radiograph taken two months before admission 

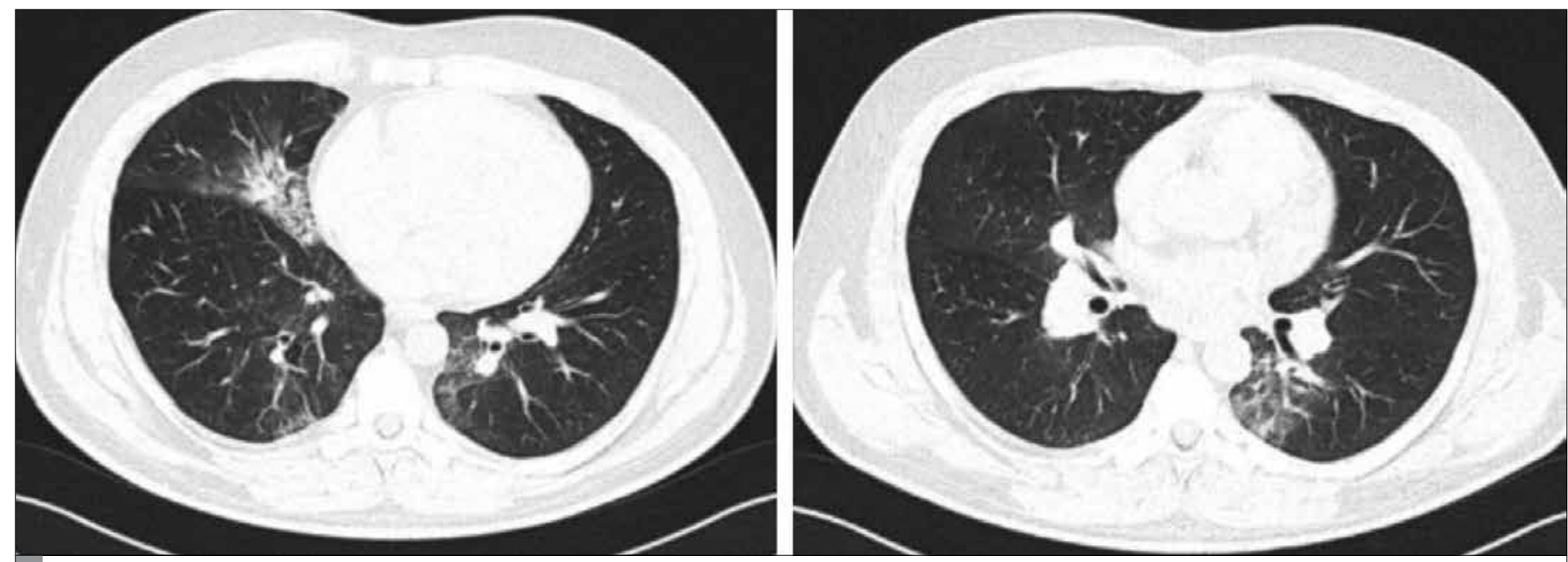

Figure 2. a, b. High-resolution computed tomography image of the thorax taken one day before hospitalization. Image of infiltration in the right middle lobe and left lower lobe superior segment

In a high-resolution computed tomography image of the thorax, patchy infiltration/ground-glass areas were observed in the right middle lobe and left lower lobe superior segment (Figure 2).
a) Atypical pneumonia
b) Hypersensitivity pneumonia
c) Pneumocystis jiroveci pneumonia
d) Pulmonary embolism
e) Bronchiolitis obliterans organizing pneumonia (BOOP)
f) Sarcoidosis

\section{What is Your Diagnosis?}




\section{Pulmonary Embolism}

The patient was hospitalized due to the findings defined above and because he was hypoxic. Because he refused to be hospitalized on the first day, the hospitalization procedure was performed the next morning. During hospitalization, the patient's dyspnea became more severe than that in the previous day, and the patient's $\mathrm{SpO}_{2}$ value was $84 \%$ at room temperature. In the arterial blood gas analysis performed at room temperature, the $\mathrm{pH}$ was 7.53, $\mathrm{pCO}_{2}$ was $24 \mathrm{mmHg}, \mathrm{pO}_{2}$ was $48 \mathrm{mmHg}$, and $\mathrm{SO}_{2}$ was $88 \%$. The patient's total leukocyte count was $8800 / \mathrm{mm}^{3}$, haemoglobin level was $17 \mathrm{~g} / \mathrm{dL}$, and platelet count was $210,000 / \mathrm{mm}^{3}$. Other leukocyte subgroups were within normal intervals. The patient's erythrocyte sedimentation rate was $9 \mathrm{~mm} / \mathrm{st}$, CRP level was $13.6 \mathrm{mg} / \mathrm{L}(\mathrm{n}<5)$, procalcitonin level was $0.04 \mathrm{ng} / \mathrm{mL}$ (low infection risk $<0.5 \mathrm{ng} / \mathrm{mL}$ ), and alanine aminotransferase (ALT) level was $58.2 \mathrm{U} / \mathrm{L}(\mathrm{n}<41)$. In the complete urinalysis, no abnormality was observed except mildly increased density. Other biochemical parameters were found to be normal.

Because the patient's $\mathrm{SO}_{2}$ level hardly increased up to $88 \%$ despite administering $5 \mathrm{~L} / \mathrm{min}$ oxygen with a nasal cannula, oxygen through a mask was administered. The patient's electrocardiogram revealed sinus tachycardia. T-wave negativity and Q-waves were observed in DIII (Figure 3). The troponin-T level ( $\mathrm{n}<14 \mathrm{ng} / \mathrm{L}$ ) was $25.9 \mathrm{ng} / \mathrm{L}$, Creatine

Table 1. The diagnosis of antiphospholipid syndrome is established in the presence of one of the following clinical criteria and one of the following laboratory criteria

\section{Clinical criteria}

\section{Vascular thrombosis}

Demonstration of one or more arterial, venous, or capillary thrombosis episodes in any tissue or organ. Thrombosis must be shown through objectively valid techniques (imaging or histopathology). In a histopathologically diagnosed thrombosis, there must be no severe inflammatory reaction in the wall of the vein.

\section{Pregnancy morbidity}

a. One or more unexplained fetal losses that are observed to have normal morphology in the ultrasound or direct examination in the 10th gestational week and later or

b. Premature birth of a baby who was morphologically normal before the $34^{\text {th }}$ gestational week due to one of the following reasons: 1) eclampsia or severe preeclampsia or 2) placental insufficiency findings.

c. Three or more unexplained miscarriage events that occur before the 10th gestational week after eliminating maternal anatomic or hormonal factors or parental chromosomal factors.

\section{Laboratory criteria}

1. Detection of two positive lupus anticoagulant results in the plasma after a 12-week interval.

2. Detection of moderate or high levels (e.g., $>40$ units) of plasma anti-cardiolipin antibody (IgG and/or lgM) measured by standard ELISA after a 12-week interval.

3. Detection of moderate or high levels (e.g., $>40$ units) of plasma anti-beta-2 glycoprotein-I antibody (IgG and/or lgM) measured by standard ELISA after a 12-week interval.

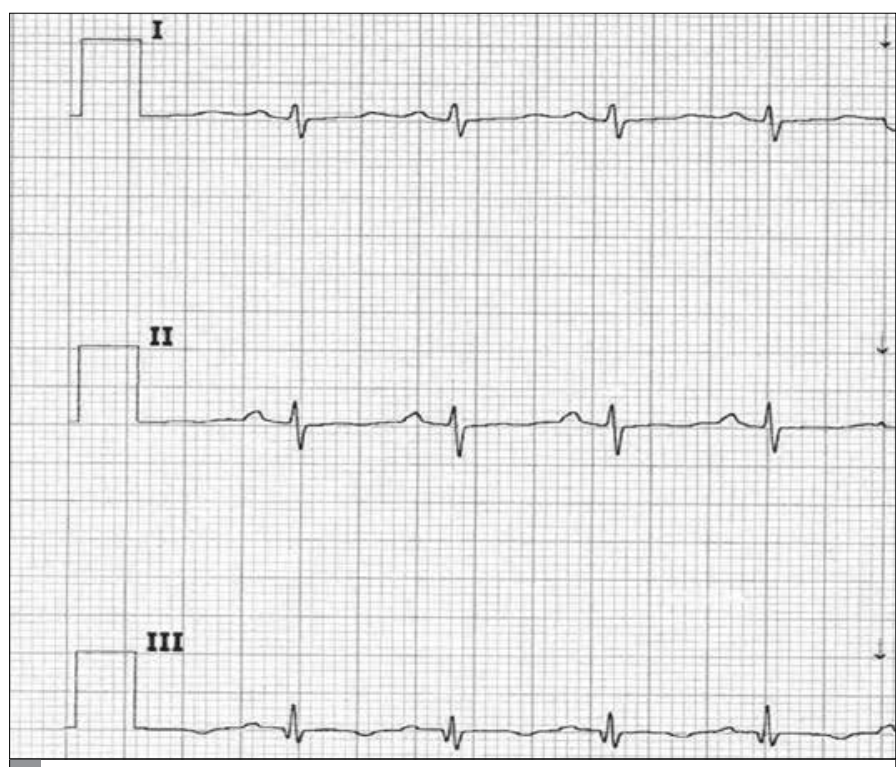

Figure 3. Electrocardiogram of the patient on hospitalization showing a typical S1Q3T3 pattern for a pulmonary embolism

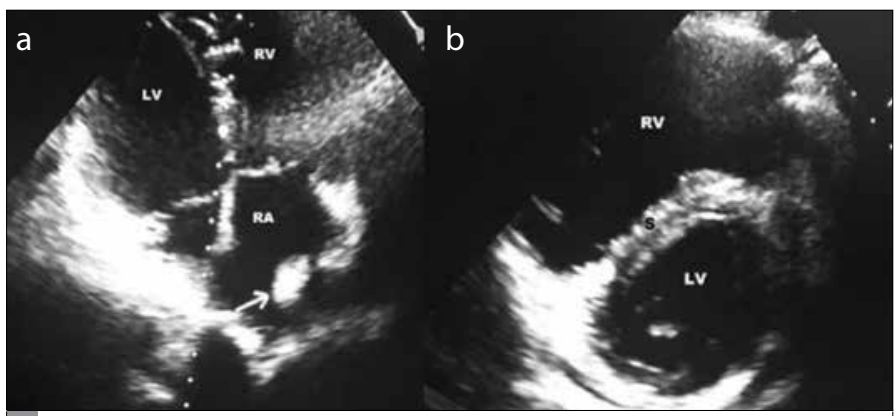

Figure 4. a, b. Echocardiography performed upon hospitalization. A thrombus in the right atrium is seen in the left image (arrow). The extent of volume reduction in the left ventricle compared to expansion in the right ventricle and the pressure on the interventricular septum are shown in the right image. LV: left ventricle; RA: right atrium; RV: right ventricle; S: interventricular septum

Kinase-MB (CK-MB) level was $12.2 \mathrm{U} / \mathrm{L}$ ( $\mathrm{n}=6$ to $25 \mathrm{U} / \mathrm{L}$ ), and pro-Brain Natriuretic Peptide (pro-BNP) level was $457 \mathrm{pg} / \mathrm{mL}(\mathrm{n}<85.8 \mathrm{pg} / \mathrm{mL}$ ).

Based on the bedside echocardiography performed the same day, the patient's left ventricular functions were normal, and the systolic pulmonary arterial pressure was $55 \mathrm{mmHg}$. An expanded right ventricle and a paradoxical septal motion were observed. A $2.1 \times 2.1-\mathrm{cm}$ sized thrombus in right atrium and minimal pericardial effusion were observed (Figure 4). From these findings, a pulmonary embolism was strongly suspected, and treatment was immediately initiated with heparin infusion. For making a definite diagnosis, computed tomography angiography of the thorax was performed.

Computed tomography angiography revealed filling defects associated with diffuse emboli distal to the right and left main pulmonary arteries (Figure 5). It was observed that the diameter of the main pulmonary artery increased compared to that of the adjacent ascending aorta and that the right atrium and right ventricle were 


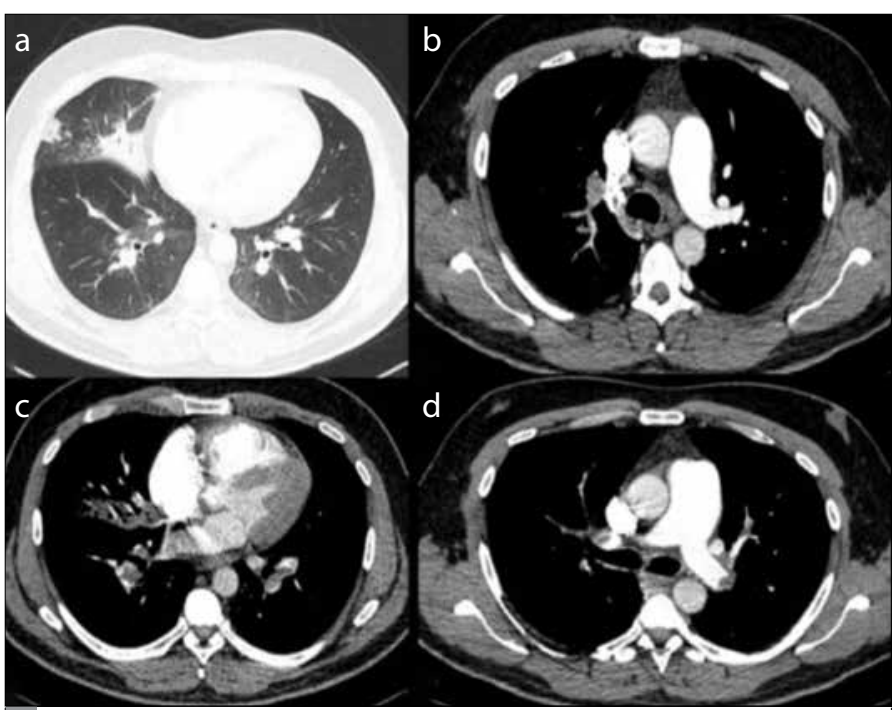

Figure 5. a-d. Contrast-enhanced thoracic computed tomography performed upon hospitalization. Increase in the area of parenchymal infiltration (a) and a newly developed subpleural component are seen. In the other mediastinal window sections, diffuse filling defects distal to the right and left main pulmonary arteries are observed $(b-d)$. The extent of the increase in the diameter of the main pulmonary artery compared to that of the adjacent ascending aorta (d) and the increased size of the right atrium and right ventricle compared to the size of the left heart chambers are seen (c)

larger than the left heart chambers. Due to severe hypoxemia and right ventricular overload findings in the echocardiography despite the stable hemodynamics of the patient, a submassive pulmonary embolism was diagnosed and alteplase was intravenously administered at a dosage of $100 \mathrm{mg} / 2 \mathrm{~h}$.

The patient responded to this treatment rapidly, and the need for oxygen decreased. After fibrinolytic therapy, anticoagulant therapy was initiated with heparin infusion, and pulmonary arterial pressure was found to be normal in the follow-up echocardiography (sPAB: $20 \mathrm{mmHg}$ ). The size of the thrombus in the right atrium was reduced to $0.5 \mathrm{~cm}$.

In the etiology analyses, the factor $V$ Leiden mutation was heterozygous positive and the prothrombin G20210A gene mutation was negative. In the evaluation of antiphospholipid syndrome (APS), Anti-cardiolipin ( $A C L$ ) IgM and $\lg G$, were negative; lupus anticoagulant (LA) was positive. Beta-2 glycoprotein 1 (GP1) IgM antibody was 108.3 $\mathrm{RU} / \mathrm{mL}(\mathrm{n}<20)$, and IgG was normal. After consultation with the Rheumatology Department, the patient was diagnosed with primary antiphospholipid syndrome by also demonstrating negativity of relevant antibodies such as anti-nuclear antibody (ANA) and anti-ds-DNA. The patient was recommended to receive lifetime anticoagulants due to the diagnosis of a submassive pulmonary embolism associated with antiphospholipid syndrome.

Antiphospholipid syndrome is a cause of recurrent thromboembolism (Table 1). It should be investigated in patients experiencing one or more venous or arterial thrombotic events with an unknown cause, particularly in young people. In contrast, it is not necessary to investigate antiphospholipid syndrome in older adults who have risk factors for venous thrombosis (1). For making a diagnosis, the increased level of at least one autoantibody defined for antiphospholipid syndrome in the serum must be demonstrated, and at least one event of arterial/venous thromboembolism or pregnancy loss must be included in the patient's medical history. There are three types of autoantibodies sought for antiphospholipid syndrome: 1) LA, 2) ACL antibodies (IgM and IgG), and 3) anti-beta-2 GP1 antibodies (IgM and IgG). In our patient, LA and anti-beta-2 GP1 IgM were found to be positive. These antibodies are investigated when a thrombotic event has occurred or when pregnancy loss occurs. After 12 weeks, the tests are repeated for confirmation. In the tests performed during thrombosis, $\mathrm{ACL}$ and anti-beta-2 GP1 antibodies are not affected by thrombus load or the presence of an anticoagulant; however, LA can be affected by these. If any of the first test results are positive, the high level of that antibody is retested after 12 weeks. The levels of these antibodies can be temporarily high in the presence of some infections or due to the use of some medications. Not every increase in antibody levels is clinically significant. Clinically significant results include LA positivity and ACL and anti-beta-2 GP1 levels at 40 units and over (1). If another cause of APS cannot be proven, the diagnosis of primary APS is established. Its treatment is similar to that for a pulmonary embolism. Heparin can be initiated and followed by warfarin. Although the treatment duration is usually lifelong, an anticoagulant can be given for three to six months after the first attack in patients with the presence of a suspected antiphospholipid syndrome diagnosis, low antibody titers, and predisposing factors for a thromboembolism attack (2).

Informed Consent: Verbal informed consent was obtained from patient who is presented in this case report.

Peer-review: Externally peer-reviewed.

Author Contributions: Concept - B.N.Ç., S.I., E.Y.; Design - B.N.Ç., S.I.., E.Y.; Supervision - B.N.Ç.; Data Collection and/or Processing - B.N.Ç., S.I., E.Y.; Analysis and/or Interpretation - B.N.Ç., S.I.., E.Y.; Literature Search - B.N.Ç., S.I., E.Y.; Writing Manuscript - B.N.Ç., S.I., E.Y.; Review - B.N.Ç., E.Y.

Conflict of Interest: No conflict of interest was declared by the authors.

Financial Disclosure: The authors declared that this study has received no financial support.

\section{REFERENCES}

1. Pengo V, Tripodi A, Reber G, Rand JH, Ortel TL, Galli M, et al. Update of the guidelines for lupus anticoagulant detection. Subcommittee on Lupus Anticoagulant/Antiphospholipid Antibody of the Scientific and Standardisation Committee of the International Society on Thrombosis and Haemostasis. J Thromb Haemost 2009; 7: 1737. [CrossRef]

2. Ruiz-Irastorza G, Cuadrado MJ, Ruiz-Arruza I, Brey R, Crowther M, Derksen $\mathrm{R}$, et al. Evidence-based recommendations for the prevention and long-term management of thrombosis in antiphospholipid antibody-positive patients: report of a task force at the 13th International Congress on antiphospholipid antibodies. Lupus 2011; 20: 206-18. [CrossRef] 